\title{
Intimate Relationships Then and Now: How Old Hormonal Processes are Influenced by Our Modern Psychology
}

\author{
Britney M. Wardecker • Leigh K. Smith • \\ Robin S. Edelstein • Timothy J. Loving
}

Received: 5 September 2014 / Revised: 13 January 2015 / Accepted: 20 January 2015 /

Published online: 10 February 2015

C) Springer International Publishing 2015

\begin{abstract}
In this review we argue that relatively recent evolutionary adaptations that are relational or psychological in nature might refocus, dampen, or otherwise shape hormonal processes related to evolutionarily "older" behaviors. We focus on the steroid hormones testosterone and estradiol and discuss a) their associations with "older relational processes" such as mate competition, dominance and nurturance, and b) the ways in which "newer relational processes" such as commitment and attachment relate to these hormones in the context of intimate relationships. We propose that these new relational processes might influence hormones in a manner that enables short-term mating relationships to be transformed into long-term romantic pair-bonds that may be unique to humans.
\end{abstract}

Keywords Mating $\cdot$ Pair-bonds $\cdot$ Testosterone $\cdot$ Estradiol $\cdot$ Evolution $\cdot$ Adaptations

Most species, including humans, have evolved some repertoire of behaviors that facilitate short-term mating (i.e., uncommitted sexual relationships that last for a short period of time, Simpson and Gangestad 1991), such as attracting desirable mates, competing for the attention of those mates, and keeping others away from mates once they have been acquired (Gangestad and Simpson 2000). These evolutionarily "old" behaviors occur frequently, can be engaged with limited conscious effort (Miller 1998), and are important components of the relationship initiation process.

Britney M. Wardecker and Leigh K. Smith are co-first authors and contributed equally to this work.

B. M. Wardecker $\cdot$ R. S. Edelstein

Department of Psychology, University of Michigan, Ann Arbor, 530 Church Street,

Ann Arbor, MI 48109, USA

L. K. Smith $(\bowtie) \cdot$ T. J. Loving

Department of Human Development and Family Sciences, The University of Texas at Austin,

Box A2702, Austin, TX 78712, USA

e-mail: leigh.k.smith@utexas.edu 
Only a few species, however, have evolved behaviors designed to deliberately maintain long-term, sexually exclusive relationships. Fewer than $5 \%$ of mammalian species establish long-term, monogamous pair-bonds with adult mating partners (Kleiman 1977). A pairbond can be defined as an enduring and close relationship between two adult members of a species that generally involves sexual activity, intimacy, the desire to be close to one another, and deep emotional investment (Hawkes 2004; van Anders et al. 2011). Among humans, the formation of these types of pair bonds is a meaningful priority. For example, forming intimate connections is reported as one of the most important human motives, sometimes even more so than is meeting basic physiological needs such as securing food and water (Kenrick et al. 2010). Indeed, there may be several benefits to successfully establishing a long-term pair-bond. Pair-bonded partners benefit from increased paternal investment, which in turn promotes offspring health (Barash 1977; Fisher 1998; Kenrick and Trost 1997). The formation of long-term pair-bonds may also decrease the risk of contracting sexually transmitted diseases (Campbell and Loving, in press), and partners who are married or committed to long-term relationships tend to live longer than their unmarried and single counterparts (Drefahl 2012; Johnson et al. 2000; Van Poppel and Joung 2001).

Yet, transforming short-term mating relationships into long-term pair-bonds might be costly psychologically. To successfully maintain long-term pair-bonds, partners must develop a sense of psychological commitment and emotional attachment to one another, forego mating opportunities with extra-pair alternatives, and, in some cases, put a partner's needs ahead of one's own (Van Lange et al. 1997). That pair-bonds are observed in almost every human culture (e.g., Kleiman 1977) suggests that, despite the cognitive and emotional resources involved in maintaining them, pair-bonds might provide benefits above and beyond those accrued via short-term mating (Campbell and Loving, in press; Kiecolt-Glaser and Newton 2001).

In this review, we examine the ways in which physiology and psychology interact to transform short-term mating relationships into long-term pair bonds. First we explore the process of establishing short-term mating relationships: attracting mates, competing for mates, and gaining sexual access to mates. Many animals, including humans, engage in these behaviors and our review will focus on the hormonal processes related to short-term mating that are common across species. We will review how hormonal processes that function to facilitate or promote short-term mating behaviors are "evolutionarily old"; their prevalence among such a wide range of species indicates that they evolved deep in our evolutionary past, prior to the phylogenetic branching that led to modern humans. We then move on to an exploration of long-term, pair-bonded relationships, and discuss more recent evolutionary adaptations that are relational or psychological in nature, and which are possibly unique to humans. We will review how these "newer" psychological adaptations (such as romantic commitment and attachment) might facilitate the development of long-term pair-bonds via their ability to dampen or refocus hormonal processes related to evolutionarily older behaviors that could undermine the formation of long-term pair-bonds (for additional work on this topic, see Eastwick 2009; Eastwick and Finkel 2012).

We have chosen to focus on testosterone and estradiol in particular because both hormones are consistently linked to mate-seeking and mate-competition processes (evolutionarily "old" behaviors that we have in common with other species), and are also influenced by psychological variables that are central to the maintenance of long-term pairbonds (evolutionarily "new" behaviors that may be unique to humans; e.g., Hohmann and 
Fruth 2003; Zehr et al. 1998). Ultimately, we argue that new psychological adaptations such as romantic commitment and attachment might interact with these two hormones to facilitate the transformation of short-term mating relationships into long-term pair-bonds.

\section{Testosterone}

Testosterone is a steroid hormone from the androgen family that is found in virtually all vertebrates, including birds, reptiles and mammals (Hirschenhauser and Oliveira 2006). Commonly thought of as a "male" hormone, testosterone plays a key role in the production of tissue for male reproductive structures; however, testosterone is vital for physical development, physiological processes, and psychological experiences in both men and women (e.g., Goldey and van Anders, in press). In the following section we review how testosterone contributes to short-term mating effort by promoting mateseeking behaviors among a variety of species and for both sexes. We also discuss how testosterone and the psychological mechanism of romantic commitment might be linked in humans in a way that promotes the development of long-term, future-oriented pair-bonds.

\section{Old Processes: Testosterone in Human and Other Animal Relationships}

Humans are one of many species - including prairie chickens, Japanese quail, pygmy goats, New Zealand rabbits, long-tailed macaques - in which testosterone is associated with mating behaviors (Augustine et al. 2011; Girard-Buttoz et al. 2009; Howland et al. 1985; Ottinger and Brinkley 1978; Saginor and Horton 1968). Across primates, mating strategies directed towards potential mates or mate-rivals are typically related to testosterone by the following rule: in species where social dominance is integral to mating success, testosterone is very tightly linked to mating effort; in species where social cooperation is essential for mating success, testosterone is more loosely linked to mating effort (Wobber et al. 2013). Consider, for example, the mating strategies of our closest primate relativescommon chimpanzees and bonobos. Chimpanzees rely heavily on dominance and aggression (e.g., physical force) to acquire mates and show dramatic increases in testosterone when competing for mates; in contrast, bonobos rely heavily on cooperation (e.g., social grooming) to acquire mates (Hohmann and Fruth 2003) and show comparatively modest increases in testosterone when interacting with potential mates (Wobber et al. 2013). These two primate species can be thought of as occupying nearly opposite ends of the mating strategy spectrum - with chimpanzees at the more socially dominant end and bonobos at the more prosocial end. As a species, humans tend to lie closer to the socially cooperative end of the primate mating strategy spectrum, making us more similar to our bonobo brethren than to our chimpanzee cousins (Cieri et al. 2014).

\section{Affiliative Behavior}

Within our species, interactions with potential mates do influence testosterone levels, but increases in testosterone are generally associated with affiliative rather than aggressive interactions between potential mates. For example, men who experienced greater increases in testosterone during a male-male competition task subsequently smiled more and made more eye contact with women than did men who experienced smaller 
increases in testosterone (van der Meij et al. 2011). In another study, women reported "clicking" more with men who had higher levels of baseline testosterone compared to men with lower levels of baseline testosterone (Slatcher et al. 2011). These studies suggest that increases in testosterone may be associated with an increase in the types of affiliative behaviors that are essential for successful interactions between potential romantic partners during the initiation stages of human relationships (e.g., courtship).

As mentioned, humans are not alone in using social affiliation to gain access to mates (Carter and Keverne 2002), and research on the mating habits of bonobos provides insight into how increased sociability between potential mates may in fact lessen the need for large increases in testosterone when acquiring mates. For example, in a bonobo community in the Democratic Republic of Congo, male bonobos who maintained more regular social contact with females via extended grooming were higher ranked in the community, had lower baseline levels of testosterone, and exhibited smaller testosterone increases in the presence of fertile females compared to males who did not maintain regular social contact with females (Surbeck et al. 2012). This research demonstrates that in species that rely on socially cooperative mating strategies, lower testosterone levels overall might facilitate affiliative behaviors that allow for more regular and extended social contact between potential mates.

\section{Dominance Behavior}

Although high levels of testosterone in humans may be associated with cooperative/ affiliative behaviors directed toward potential mates, high testosterone is typically associated with dominance behaviors between rivals for mates. For example, when men competed for the favor of a desirable woman, those with higher baseline testosterone levels were more likely to direct displays of social dominance toward their competitor and were more likely to report that their competitor was unlikeable. Additionally, men who reported the highest levels of social dominance showed the strongest association between testosterone levels and competitive behaviors (Slatcher et al. 2011). In another example, men's testosterone levels showed larger increases from baseline when they were exposed to a competitive (versus uncompetitive) male in the company of a highly fertile (versus less fertile) female (Fales et al. 2014). In fact, even the mere presence of potential mates in a competitive setting can elicit testosterone increases in both men and women (López et al. 2009; Roney et al. 2007).

Although increases in testosterone facilitate some competitive behaviors for mates in humans, it is important to note that, in most cases, testosterone increases do not facilitate the extreme levels of dominance and aggression observed in primates such as chimpanzees. For example, increases in testosterone in chimpanzees sometimes lead to exceedingly violent mate guarding behaviors such as territorial boundary patrols wherein males brutally attack and often kill neighboring males, especially if fertile females are residing within their own territory (Sobolewski et al. 2012). Additionally, chimpanzees regularly aggress against both male and female conspecifics when competing for mates. Data collected over 11 years of observing a chimpanzee community in Uganda revealed that male chimpanzees with high testosterone achieved the most mating success with the females they showed the most physical aggression toward (Muller et al. 2011); given the mostly consensual nature of human mating, it is difficult to imagine the same pattern of results emerging in our own species. Although violent sexual coercion and rape are not 
absent in the human species, such behaviors are often (but not always) culturally condemned and typically considered psychopathological (for a review see Gannon and Ward 2008). Surveys have reported that approximately 5-15\% of college age men have admitted to committing forced sex or rape (Koss et al. 1987). While this percentage is still unacceptably high, it is in stark contrast to observations across multiple chimpanzee communities where aggressive sexual coercion against fertile females appears to be the norm; that is, virtually all healthy chimpanzee males will likely engage in multiple acts of forced sex during their lifetimes (for a review see Muller et al. 2009a; Smuts and Smuts 1993). In summary, although elevated testosterone in humans is related to increased social dominance during mate competition, our species has also evolved strategies to obtain mates that need not involve violence or sexual coercion to be successful. Taken together this may suggest that, comparatively, we fall closer to the socially cooperative end of the mating strategy spectrum overall.

\section{Reconciling Physiology and Behavior}

As reviewed above, hormones are often associated with behavior in the mating context, but the association between physiology and behavior is complex. Specific physiological processes are not necessarily always associated with predictable behavioral outcomes. For example, humans and chimpanzees have very similar fluctuations in testosterone across the lifespan - testosterone rises exponentially during puberty and then declines slowly over time - yet the behaviors humans and chimpanzees use to obtain mates are exceedingly different (August et al. 1972; Sizonenko and Paunier 1975; Yeap et al. 2007). Furthermore, there are many similarities between the socially cooperative mating strategies of humans and bonobos, but some research suggests that humans and bonobos have very different fluctuations in salivary testosterone across the lifespan (Wobber et al. 2013), whereas other research suggests that humans and bonobos have very similar fluctuations in urinary testosterone across the lifespan (Behringer et al. 2014). Further still, despite potential similarities in testosterone levels across the lifespan and a tendency to engage in socially cooperative mating, bonobos do not form long-term pair-bonds such as those observed among humans. Put simply, testosterone levels alone cannot predict what types of mating behaviors a species will engage in and the shape their social relationships will take.

This observation leads to an important question regarding the association between physiology and behavior: What factors can we explore beyond and in conjunction with physiology to better understand the association between testosterone levels and mating behaviors in humans? One candidate factor is the psychological construct of romantic commitment. In the next section, we review how greater romantic commitment to a partner might constrain or be dampened by circulating testosterone levels in humans (e.g., Edelstein et al. 2014), as well as how greater romantic commitment might promote cooperative, rather than aggressive, behaviors in mating relationships. We also review how lower levels of testosterone may be associated with an increased likelihood of forming committed romantic relationships.

\section{A Newer Psychological Adaptation: Romantic Commitment}

The construct of romantic commitment entails in large part a long-term orientation toward one's partner (Wieselquist et al. 1999). Commitment is typically measured with 
items that tap into a desire for longevity (e.g., "I want my relationship to last a very long time"), future-oriented thinking about the relationship (e.g., "I can imagine being with my partner several years from now"), and psychological attachment (e.g., "I feel very attached to my relationship and feel strongly linked to my partner"; Arriaga and Agnew 2001; Rusbult et al. 1998). Commitment is one of the strongest predictors of relationship persistence over time (Drigotas and Rusbult 1992; Le and Agnew 2003).

Humans are likely one of the only species who are able to reflect upon and report the degree to which they intend to invest and persist in a relationship. By definition, romantic commitment involves a cognitive adaptation that is relatively new in the evolutionary timeline: future-oriented thinking (Atance and O'Neill 2001; Gilbert and Wilson 2007). Although virtually all animals are capable of predicting the consequences of situations they have experienced in the past, humans are uniquely able to predict the consequences of experiences they will have in the future (Tulving 2005). Romantic commitment, for example, requires us to mentally travel into the future and to picture our relationships at a future time. Future-oriented thinking takes place largely in the pre-frontal cortex and temporal medial lobes (Suddendorf et al. 2009), areas of the brain that are more complex in humans compared to other primates (Teffer and Semendeferi 2012), suggesting that few if any other animals can engage in prospective thinking (Schacter et al. 2007; Szpunar et al. 2007).

Because romantic commitment entails an investment in a relationship's future, committed partners should be motivated to engage in strategies that will increase the likelihood of maintaining a high quality relationship over time. Indeed, high levels of romantic commitment to a partner are associated with a range of pro-relationship behaviors such as being more likely to forgive a partner's transgressions (Finkel et al. 2002), making sacrifices that will benefit a partner (Van Lange et al. 1997), and supporting a partner's personal goals (Hui et al. 2014). Strong commitment to a partner also decreases the likelihood of destructive relationship behaviors. For example, partners who are highly committed to a relationship report less infidelity (Le et al. 2010) and are less likely to display hostility and aggression during conflict resolution (Oriña et al. 2011; Slotter et al. 2012). For example, Slotter et al. (2012) exposed couple members to a series of increasingly severe partner provocations (e.g., harsh criticism from a partner, partner flirting with another person) and found that participants who were low in romantic commitment expressed more verbal and physical aggression toward their partners as the intensity of the provocations increased, whereas partners who were high in commitment did not. These studies suggest that romantic commitment may inhibit the severity of both conflict and aggressive behaviors in relational contexts.

Importantly, high levels of romantic commitment have been associated with lower levels of testosterone (Burnham et al. 2003) and lower levels of testosterone are related to fewer aggressive thoughts and behaviors in a diverse range of contexts (Archer et al. 2005). Thus, the forward-looking nature of romantic commitment may be associated with the dampening of one's testosterone levels that, left otherwise unconstrained, might interfere with the maintenance of long and healthy romantic relationships. Lower levels of testosterone might also be related to increases in romantic commitment, for instance by reducing interest in alternative relationship partners (e.g., Edelstein et al. 2011; McIntyre et al. 2006). 


\section{Romantic Commitment Modulates Testosterone}

The association between commitment and testosterone has been mostly documented through indirect measures of romantic commitment, including relationship status, marital status, relationship length, (lack of) interest in alternative partners, and a restricted socio-sexual orientation (e.g., Edelstein et al. 2011; Hooper et al. 2011; McIntyre et al. 2006; van Anders and Goldey 2010), which all communicate in part the degree to which an individual intends to persist in a relationship. In the following section, we categorize the various methods that have been used to infer romantic commitment into two primary groups: relationship status indicators of romantic commitment and dispositional/behavioral indicators of romantic commitment, and discuss their associations with testosterone levels in the context of close relationships.

Relationship Status Indicators The vast majority of research on romantic commitment and testosterone has been conducted using self-reported relationship status (i.e., how individuals self-define the current state of their relationships) as an indicator of romantic commitment. Earlier research focused mainly on men's marital status, and demonstrated that men who reported being married had lower levels of testosterone than their unmarried counterparts (e.g., Booth and Dabbs 1993; Gray et al. 2002; Mazur and Michalek 1998). Importantly, one longitudinal study demonstrated that men's testosterone levels changed as a function of their marital status (Mazur and Michalek 1998): participants' testosterone levels increased after divorce as commitment to the relationship presumably decreased and motivation to obtain a new mate most likely increased, and testosterone levels decreased following remarriage as commitment to the new relationships likely increased and motivation to obtain a new mate most likely decreased.

Although early studies on testosterone and relationship commitment generally focused on men, more recent work indicates that women who are married also have lower testosterone than their non-married counterparts (Kuzawa et al. 2010; van Anders and Watson 2006). Research with couples further demonstrates that both men and women are more committed to and satisfied with their relationships to the extent that their partners have lower levels of testosterone (Edelstein et al. 2014). These dyadic effects are larger for women's than for men's testosterone, suggesting that individual differences in women's testosterone may be particularly reflective of or responsive to differences in men's relationship quality. Together, these findings suggest that higher levels of testosterone may be helpful in terms of attracting mates and initiating romantic relationships, but that increased commitment to those relationships may decrease testosterone over time.

Contemporary research examining the association between relationship status and testosterone levels has expanded study samples to include a larger range of relationship types that go beyond simply being "married" or "unmarried". For example, Burnham et al. (2003) categorized their male participants as either "paired" (i.e., in committed, romantic relationships) or "unpaired" (i.e., not in committed, romantic relationships) and suggested that the lower levels of testosterone observed in paired men was linked to being socially bonded and psychologically committed to another person rather than simply being married. After all, there are certainly people who are married but are not necessarily committed to the long-term future of their relationships (Treas and Giesen 2000). In another example, Gray et al. (2006) demonstrated that carefully dividing relationship categories into ever more discrete groups yields a more complete story of 
how commitment is related to testosterone. In order of lowest to highest commitment, their sample included single men, men who were married, and men who were married with children. As commitment level increased across this cross-sectional sample, testosterone levels decreased. In another study, van Anders and Goldey (2010) examined differences in testosterone among men and women who identified as single, casually dating (i.e., relationship(s) that may involve sexual activity and romance but not commitment), or partnered (i.e., committed long-term romantic relationships) and found that men who were single and in casual relationships had higher levels of testosterone compared to men in long-term relationships. Interestingly, women in casual relationships had significantly lower testosterone than did single women, and women in long-term relationships showed a statistical trend for lower testosterone levels than did single women. Women in casual and long-term relationships did not significantly differ in their testosterone levels. These findings suggest that degree of commitment may be more closely tied to men's compared to women's testosterone levels (see also van Anders and Watson 2007). Taken together, this research highlights potentially important gender differences in the link between testosterone and relationship commitment.

Measures of romantic commitment have also been useful in understanding crosscultural associations between marital status and testosterone. The norms for what constitutes commitment may be highly variable depending on socioeconomic, ecological and political factors (Jankowiak and Fischer 1992), which means that marriages among Hadza foragers, Kenyan Swahili couples, partners in Beijing China, and Harvard business students may not be cross-culturally equivalent in terms of commitment expectations. If commitment modulates the expression of testosterone in romantic relationships, then marital status alone may not always be sufficient to reveal group differences in testosterone levels. For example, in a study conducted in Beijing, China, testosterone levels of married men were lower than unmarried men, but this difference failed to reach conventional levels of statistical significance. The commitment norms of this Beijing sample reveal important information concerning why this hypothesis test may have failed: specifically, the proportion of men who reported having more than one sex-partner in the previous year was higher among married men than unmarried men (Gray et al. 2006). This suggests that although these men had formally committed to a legal marriage they did not necessarily endorse a sexually exclusive commitment to their wives, which perhaps explains their comparatively high levels of testosterone. In another study conducted among Swahili men living in Kenya, researchers found that, contrary to expectations, men who were married had higher levels of testosterone than unmarried men (Gray 2003). Critically, the tradition of marriage in this culture included the possibility of having multiple wives, suggesting that commitment to a single individual was not a strict cultural expectation of marriage, and that marital status alone could therefore not be used as a reliable proxy for romantic commitment. The possibility of having multiple and/or new partners has also been associated with higher testosterone in other cultures (van Anders 2009). For example, in North America, men and women who engaged in emotional and/or sexual relationships with multiple partners simultaneously (i.e., polyamorous individuals) versus one partner (i.e., monoamorous individuals), had significantly higher levels of testosterone than monoamorous men and exhibited a trend for higher testosterone than single men; polyamorous women had significantly higher levels of testosterone than both monoamorous and single women (van Anders et al. 2007). Perhaps sexual exclusivity 
or engaging in sex with only one partner, rather than relationship status, is the aspect of commitment that is most important for modulating testosterone in humans across various cultures. Thus, if cultural norms do not support a cohesive, exclusive pairbond, researchers should consider directly measuring partners' commitment levels using constructs beyond relationship status.

Dispositional \& Behavioral Correlates Romantic commitment can also be indexed via a partner's disposition toward the relationship. One such dispositional construct is called sociosexual orientation, which is designed to assess an individual's personal sexual history, frequency of sexual fantasies, and attitudes toward casual, uncommitted sex. Those who have highly unrestricted sociosexual orientations tend to endorse items such as "sex without love is okay" and "I can imagine myself enjoying casual sex with multiple partners." Sociosexual orientation predicts the type of romantic partner a person will choose (Simpson and Gangestad 1992), how quickly individuals initiate sex after starting a new relationship (Simpson and Gangestad 1991), one's lifetime number of sexual partners (Ostovich and Sabini 2004), one's likelihood of cheating on his or her partner, and one's likelihood of listing "sex" as the motive for infidelity (Barta and Kiene 2005).

An increasingly unrestricted sociosexual orientation is also strongly and negatively associated with explicit measures of relationship commitment (Hackathorn and Brantley 2014; Markey and Markey 2013) as well as with levels of salivary testosterone (McIntyre et al. 2006). For example, McIntyre et al. (2006) found that paired men who were interested in engaging in sexual activities with women other than their primary partners had higher levels of testosterone than paired men who did not desire extra-pair sexual contact. This finding highlights how commitment can direct hormonal resources away from the immediate rewards of infidelity in anticipation of the future gains afforded by psychological commitment. Alternatively, it is also possible that higher testosterone levels increase men's desire for extra-pair sexual contact, making commitment more psychologically difficult for some men than others. However, other studies have not found significant associations between partnered individual's testosterone and their sociosexual orientation (e.g., van Anders and Watson 2007).

It is important to differentiate between people's attitudes, desires and behaviors. Sociosexuality itself can be split into these three components (Penke and Asendorpf 2008), and doing so has allowed researchers to better understand what dimensions of commitment are most strongly related to individuals' testosterone levels. For example, Edelstein et al. (2011) found that men who were in a relationship but reported a greater desire for uncommitted sexual activity had testosterone levels that were similar to those of men who were not in a relationship. Women who reported more uncommitted behaviors also had testosterone levels that were similar to single women. Overall measures of sociosexual orientation were positively associated with testosterone in men but not women. These findings again highlight the important role of relationship status and suggest that, especially in women, testosterone may not be linked to overall sociosexual orientation, but instead to specific components of sociosexuality, such as desire (e.g., "How often do you experience sexual arousal when you are in contact with someone with whom you do not have a committed romantic relationship?") and behavior (e.g., "With how many different partners have you had sexual intercourse on one and only one occasion?"), respectively.

One particularly important behavioral indicator of an individual's intent to persist in a relationship may be having children with his or her partner, which typically entails 
large emotional, physical, financial, and social investments (Twenge et al. 2003). Accordingly, many studies demonstrate that parents have lower testosterone levels compared to non-parents (Barrett et al. 2013; Gettler et al. 2011; Gray et al. 2002; Hirschenhauser et al. 2002; Kuzawa et al. 2009; Pollet et al. 2013). Although more attention has been paid to testosterone changes associated with fatherhood, studies of women similarly suggest that mothers have lower testosterone than women without children (Barrett et al. 2013; Kuzawa et al. 2010). However, having a child per se may not directly account for the lower testosterone levels documented in parents versus nonparents. Level of direct care provided by the parent may instead and/or also account for the association between reduced testosterone and parenting (Gettler et al. 2011). For example, Muller et al. (2009b) compared the differing parenting styles of fathers in two different East African groups: Hadza foragers and Datoga pastoralists. Hadza fathers, who are characterized as having high involvement with their children, had lower testosterone levels than Hadza non-fathers; Datoga fathers, who are known to provide minimal paternal care, had similar testosterone levels to Datoga men who were not fathers (Muller et al. 2009b). Thus, the direct level of parental care may be more closely associated with men's testosterone levels than the status of having a child or not.

Moreover, longitudinal research suggests that men's testosterone declines pre-to postnatally (Gettler et al. 2011), and that such declines may begin during the prenatal period (Edelstein et al. 2014). These findings suggest that fatherhood may alter men's testosterone levels, rather than men with lower testosterone being more likely to become fathers (see also Gettler et al. 2011). Psychologists most frequently explain these findings in terms of the tradeoff between mating effort and parenting effort (Gangestad and Simpson 2000; Wingfield et al. 1990). That is, resources are either directed toward searching for new mates or toward rearing children to reproductive age with current mates. It seems plausible, then, that romantic commitment between pair-bonded parents plays a role in lowering testosterone levels, and that lower testosterone levels may help to maintain a stable family structure.

\section{Summary}

In sum, indicators of romantic commitment are consistently associated with lower testosterone levels among modern humans, whether indexed via relationship status, dispositional, or behavioral measures. As such, it is possible that the adaptations that evolved to support a future-oriented commitment to one's romantic partner also function in part to manage the comparatively self-interested, impulsive behaviors typically associated with increased testosterone in the mating domain (e.g., infidelity, risk-taking, displays of aggression). Furthermore, the dampening effect of romantic commitment on testosterone in humans may act in the service of transforming shortterm mating relationships into long-term romantic pair-bonds.

\section{Estradiol}

Estradiol is the most behaviorally potent form of estrogen in humans and other mammals. This steroid hormone has been linked with processes central to acquiring mates, such as dominance and sexual motivation, as well as to processes essential for 
maintaining close relationships, such as caregiving, bonding, and sexual intimacy (e.g., Edelstein et al. 2012; Stanton and Schultheiss 2009; van Anders et al. 2009; WynneEdwards and Reburn 2000). Although estradiol is often thought of as a "female" hormone, sex differences in estradiol are generally very small in most species, particularly in comparison to sex differences in testosterone (e.g., Konkle and McCarthy 2011). Moreover, as discussed more fully below, estradiol is linked with relationship processes in both females and males across a wide range of species, including modern humans. As we note, in many cases the role of estradiol is similar across sex, but in some contexts there are important sex differences.

Old Processes: Estradiol in Human and Other Animal Relationships

\section{Dominance Behavior}

Many animals use dominance behaviors to claim or maintain access to social resources, including sexual partners, and to protect offspring (Lindenfors and Tullberg 2011). Although males are typically thought to be more competitive and aggressive in terms of reproduction and mate/offspring defense (Archer 2009), females also display certain types of behavioral aggression with regard to social resources (Chevalier-Skolnikoff 1974). Both female and male macaques, for instance, use forceful hip motions and bites as displays of strength or power to inhibit subordinates from attempts to acquire their sexual opportunities or offspring (Chevalier-Skolnikoff 1974; Maestripieri 1997, 2005).

In many female primates, dominance-related behaviors such as assertive body postures, vocal threats and physical attacks have been associated with higher estradiol concentrations (e.g., Bouissou 1990; Michael and Zumpe 1993). For example, female Syrian hamsters treated with estradiol or testosterone showed significantly less submissive behavior when an intruder was placed in their cage compared to untreated animals or those treated with other hormones (Faruzzi et al. 2005). Higher-ranking female rhesus monkeys treated with estradiol also displayed more physical threats and chases towards other female monkeys who were perceived as mate competition (Zumpe and Michael 1989).

In male animals, dominance has been linked with higher levels of testosterone, including in the context of mating behavior (e.g., Beehner et al. 2006). However, testosterone is naturally converted to estradiol (via aromatization) in humans and other species (see Hau 2007) and estradiol, at times in combination with testosterone, may contribute to dominance behaviors once thought to be exclusively associated with testosterone. For example, in male mice, bites and displays of anger are positively correlated with increases in testosterone (vom Saal 1983) and with the activation of neural pathways that are associated with estrogen receptors (Newman 1999; Trainor et al. 2008; Wu et al. 2009). Yet the exact relationship between estradiol and male dominance behaviors remains somewhat unclear. Estradiol appears to increase male aggression in some species (e.g., domestic mice) but decreases aggression in others (e.g., California mice, see Trainor et al. 2006 for a review). Potential explanations for species variation in the estradiol-aggression link include differences in the expression of estrogen receptors, differences in where in the brain aromatization occurs, and differences in how the social context affects aromatase function (Trainor et al. 2006). 
In humans, dominance has typically been measured by assessing people's selfreported (or explicit) dominant behaviors and inclinations (e.g., van der Meij et al. 2008). Other, more indirect methods of dominance have also been used, such as behavioral observation (e.g., Slatcher et al. 2011) and assessments of people's unconscious (or implicit) need for power (i.e., concern with having impact on and dominance over others; Schultheiss 2008). In women, these implicit (rather than explicit) measures of dominance and power motivation have been linked to endogenous estradiol levels (Stanton and Schultheiss 2009). For example, in response to a laboratory dominance contest, women with higher implicit power motivation experienced estradiol increases after winning the contest and estradiol decreases after losing (Stanton and Schultheiss 2007). These findings suggest that competitive experiences that typically increase testosterone in men might instead (or additionally) increase estradiol in women. Of note, women's testosterone is generally unrelated to their implicit power motivation (Stanton and Schultheiss 2007).

Other studies have demonstrated a positive association between women's salivary estradiol and implicit power motivation, and these associations appear to be stronger for women who are single (vs. those who report being in a romantic relationship) and those who are naturally cycling (vs. taking hormonal contraceptives; Stanton and Edelstein 2009; Stanton and Schultheiss 2007). Given that dominance motivation and estradiol are both positively associated with the frequency of women's sexual activity (Geary 2010; Schultheiss et al. 2003), it is possible that estradiol facilitates increased dominance behaviors (or vice versa) in the service of successfully competing for potential mates. That the link between implicit power motivation and estradiol levels is strongest for single women further suggests that increases in estradiol may be geared toward mate competition, as single women may be more motivated to seek out mates compared to women who are in romantic relationships. Moreover, oral contraceptive use might interfere with the association between women's estradiol and their implicit power motivation by artificially dampening women's endogenous estradiol levels.

\section{Sexual Behavior}

For all species that rely on mating to produce offspring, sexual behavior is central to reproductive success; however, sexual behavior is most adaptive when it is sensitive to contextual factors such as mate quality, likelihood of conception, and the safety of the environment (Kenrick et al. 2013). In other words, species are most likely to pass on their genes to the next generation if their sexual behaviors are attuned to their environments and to potential mates (Buss and Schmitt 1993).

Estradiol may be an important contributor to sexual behavior and motivation, particularly in females (e.g., rhesus monkeys; Wallen et al. 1984; Zehr et al. 1998). For instance, in many mammals, female sexual receptivity is at least initially dependent on processes associated with estradiol (Pfaff 1980; Rissman et al. 1997). In fact, estradiol may even increase sexual behaviors in the absence of reproductive opportunities. For instance, young sexually inexperienced female rhesus monkeys treated with estradiol during the nonbreeding season engaged in a higher frequency of same-sex but not opposite-sex sexual behavior (Pope et al. 1987). In contrast, older sexuallyexperienced female rhesus monkeys treated with estradiol during the nonbreeding season displayed a higher frequency of opposite-sex but not same-sex interactions 
(Zehr et al. 1998). These findings suggest that estradiol may increase female sexual motivation, but the target of sexual behavior may depend on contextual factors such as an animal's seasonal variations in sexual motivation and previous sexual experiences.

Although the role of estradiol in male sexual behavior has been less extensively investigated, a few studies have demonstrated that estradiol is also involved in (and in some cases essential to) male sexual behavior. For instance, male mice housed near females show an increase in urinary estradiol over a period of several days (deCatanzaro et al. 2009). Male rats treated with estradiol are also more sexually receptive towards females, display a greater number of sexual mounts, and have a more consistent ejaculatory pattern over time (Antonio-Cabrera and Paredes 2012). Furthermore, when estrogen receptors are knocked out and/or the aromatization of testosterone to estradiol is inhibited, male mice are less likely (and even unable) to engage in social investigation (e.g., licking of a female's genital area) and sexual chasing of female mice (Ogawa et al. 2000). Male mice lacking estrogen receptors are also less receptive to females' sexual advances (Ogawa et al. 2000).

Estradiol is also related to sexual behaviors in humans, but as in other animals, context and individual experience matter. For example, in one study, viewing erotica led to increases in women's estradiol; however, increases in estradiol were associated with women's genital sexual arousal (a physical experience) but not their self-reported sexual arousal (a psychological experience; van Anders et al. 2009). Furthermore, van Anders and Dunn (2009) found that women's physical experiences of solitary sexual activity (e.g., masturbation) were positively associated with endogenous estradiol levels, whereas women's psychological experiences of solitary and partnered sexual desire (e.g., relaxation) were not associated with estradiol. In men, estradiol was not related to either physical or psychological components of sexuality (van Anders and Dunn 2009). Findings from both of these studies support the idea that estradiol is most strongly related to physical, rather than psychological, experiences of sexual arousal, but perhaps specifically in women.

From an evolutionary perspective, women's sexual behaviors may be more closely linked to estrogen levels when the chance to reproduce is greatest. That is, increases in estradiol just prior to ovulation might motivate women to engage in frequent sexual behavior with higher quality mates to maximize the probability of conceiving genetically fit offspring. However, research in support of the claim that increases in estradiol motivate women to engage in sex for the explicit purpose of reproduction is mixed; some studies suggest that sexual desire is instead oriented around factors such as pleasure, power, or intimacy (e.g., Diamond and Wallen 2011). For example, women with consistent patterns of same-sex sexuality (compared to inconsistent or fluctuating patterns and bisexuals) experienced significantly larger increases in sexual motivation and desire for sex with other women during peak levels of estrogen (Diamond and Wallen 2011). This implies that increased estrogen during peak fertility is closely related to sexual motivation generally, regardless of whether the resultant sexual activity will produce offspring.

\section{Nurturant Behavior}

In addition to facilitating mate-acquisition behaviors such as displays of dominance and increased sexual motivation, estradiol is related to a range of behaviors that facilitate 
social bonding, such as nurturance and intimacy. Nurturant behavior often takes the form of parental caregiving to promote infant survival (Bowlby 1969; Simpson and Belsky 2008) but it can also be more broadly defined as "warm and loving contact between individuals," which applies to non-filial relationships such as romantic pairbonds (Brennan et al. 1998; Cassidy 2000; Fraley and Shaver 2000; van Anders et al. 2013). Nurturance is adaptive across species and relationship contexts in that it strengthens social connections and contributes to offspring and parental fitness (Fernandez-Duque et al. 2009; Simpson and Belsky 2008). In marmosets and tamarins, for instance, offspring fitness is enhanced when there is a strong pair-bond between parents and direct father-child caregiving (Snowdon 1996). Parental fitness is also enhanced through care from adult partners. For example, owl monkeys are among the most monogamous primate species, and owl monkey fathers are involved in the care of their offspring. Male owl monkeys provide their pregnant female partners with nutrition to keep mother and baby healthy during gestation (Wolovich et al. 2008), which likely enhances offspring survival and promotes social bonds between adults and children.

Estradiol contributes to many components of nurturant behavior in mammals. In female mammals, estradiol increases significantly during pregnancy, spikes just prior to birth, and drops precipitously thereafter (Yoshinaga et al. 1969). Pre-birth increases in estradiol are thought to be associated with maternal care (Maestripieri and Zehr 1998; Numan 1994; Pryce 1996; Rosenblatt et al. 1998; Wynne-Edwards and Reburn 2000) and women who experience smaller declines in estradiol from late pregnancy to the early postpartum, self-report the highest levels of nurturance and feelings of attachment to their new babies (Fleming et al. 1997), suggesting that higher levels of estradiol support nurturant behavior. In female rats, licking and grooming of pups can activate estrogen receptors, suggesting that nurturant behavior can feed back to influence the neural mechanisms that support maternal care (Champagne et al. 2001).

Although similar neuroendocrine pathways are thought to support maternal and paternal behavior, findings linking estradiol with male nurturant behaviors are less consistent (Reburn and Wynne-Edwards 1999; Wynne-Edwards 2001). For instance, when male California mice, a species characterized by a monogamous social configuration and biparental care, were treated with estradiol, they displayed increased paternal behavior in the form of huddling and pup grooming (Trainor and Marler 2002). However, in male prairie voles, also characterized as monogamous and biparental, increases in estradiol led to higher levels of aggression towards pups and less caregiving behavior (Cushing et al. 2008). Thus, as with male aggression, in some species estradiol appears to promote paternal behavior, but in other species estradiol may inhibit paternal behavior (Wynne-Edwards and Reburn 2000). More precise explanations for these differences await further investigation.

In humans, nurturant behavior is most often studied in the context of parent-child relationships, but is also a central component of adult romantic relationships (Brennan et al. 1998; Chopik et al. 2014; van Anders et al. 2013). As in animals, human nurturant behavior has been associated with endogenous estradiol concentrations and estradiol responses, although there may be sex differences in these neuroendocrine processes (Mileva-Seitz and Fleming 2011). For instance, increases in estradiol during pregnancy may facilitate maternal behavior and mother-infant attachment (Fleming et al. 1997). There is also evidence, albeit limited, that new fathers have higher estradiol levels 
compared to men without children (Berg and Wynne-Edwards 2001), suggesting that estradiol might similarly facilitate paternal behavior. However, the role of estradiol in human paternal behavior is not yet well understood (Wynne-Edwards and Reburn 2000) and short-term longitudinal research suggests that the estradiol levels of expectant fathers may in fact decline throughout the prenatal period (Edelstein et al., in press). As discussed previously, estradiol appears to facilitate paternal behavior in some animal species (e.g., California mice, see Trainor et al. 2006); however, estradiol can inhibit paternal behavior in other species (e.g., prarie voles, Cushing et al. 2008). Although more research is clearly needed, it is possible that preemptive declines in estradiol inhibit dominance behaviors or mating effort that are incompatible with the transition to fatherhood. Perhaps men's estradiol decreases prenatally in order to mitigate such behaviors, but then increases in the postpartum period to facilitate nurturance (Berg and Wynne-Edwards 2001). Future research that assesses the trajectory of estradiol concentrations throughout different relationship transitions, from beginning an intimate relationship to starting a family, can help to shed light on the role of estradiol in nurturant behavioral contexts.

\section{Mating Motives Versus Bonding Motives}

In certain contexts, estradiol is associated with behaviors related to mate competition and sexual contact, but in other contexts estradiol is associated with behaviors that are central to fostering intimacy and establishing social connections. For instance, in women and other female animals, estradiol has been associated both with dominance in the context of competition (e.g., Stanton and Schultheiss 2007) and with nurturance in the context of parental interactions (e.g., Champagne et al. 2001). How can researchers more fully understand the seemingly contradictory roles of estradiol? One mechanism worth exploring is psychological attachment to a relationship partner. In the next section, we explore the role of individual differences in attachment in the creation and maintenance of social bonds. We also explore how individual differences in attachment can moderate the expression of estradiol in the context of acquiring new mates and nurturing long-term relationships.

\section{A Newer Psychological Adaptation: Romantic Attachment}

Individual differences, such as personality traits, can influence how humans experience their social environment and how their hormones respond to those environments (Netter 2004). Recent work suggests that attachment orientation, or people's characteristic approach to close relationships (Shaver and Mikulincer 2007) may be particularly relevant for neuroendocrine processes (Simpson and Rholes 2012), including estradiol levels and responses (Edelstein et al. 2012, 2010). Attachment theory was initially developed to describe the nature of bonds between infants and their caregivers, and to explain how infant behaviors, such as crying, proximity-seeking, and clinging, help to promote parental protection and infant survival (Bowlby 1969). Parent-infant attachment relationships are present in many species; however, in humans and some other mammals, the same behavioral system that underlies parent-infant attachment is also thought to underlie adult pair-bonding and/or romantic attachment (Ainsworth 1989; Hazan and Shaver 1987; Zeifman and Hazan 2008). For example, people who 
are in stable long-term romantic relationships are more likely to report that they direct attachment behaviors, such as proximity-seeking and separation distress, toward their current romantic partner than toward anyone else in their lives (Hazan and Zeifman 1994).

Adult pair-bonding is a relatively rare phenomenon in other mammalian species (Kleiman 1977). However, throughout our evolutionary history, species that did form pair-bonds also shared many other characteristics with modern humans: They were more likely to show bi-parental care, had longer lifespans, took longer to leave the nest or home, were generally smaller in size, and were part of smaller social groups (Fraley et al. 2005). These findings suggest that the attachment behavioral system, which functioned to bond infants to caregivers, may have been modified by natural selection to bond adult romantic partners to one another (see also Eastwick 2009).

Human romantic attachment is measured in a variety of ways, but the most common measures tap into a desire to share intimate details with one's partner as well as a belief that one can depend on one's partner for support (Brennan et al. 1998). Individuals who are avoidantly attached tend to agree with statements such as "I get uncomfortable when a romantic partner wants to get too close" and "I prefer not to show a partner how I feel deep down"; individuals who are anxiously attached tend to agree with statements such as "I worry that my partner doesn't really love me," and "It makes me mad that I don't get the affection and support I need from my partner." Securely attached individuals report low levels of both attachment avoidance and attachment anxiety. As we describe next, attachment orientations are consistently related to relationship outcomes, including neuroendocrine processes.

\section{Attachment Bonds Moderate Estradiol-Relationship Associations}

Variations in the strength and type of romantic attachment bonds may help to explain why higher levels of estradiol are sometimes associated with greater mating effort and other times with greater bonding effort. For example, in one study, men and women with less avoidant (i.e., more secure) trait attachment orientations had higher levels of endogenous estradiol, particularly if they also had high levels of implicit intimacy motivation (i.e., desire for closeness; Edelstein et al. 2010). Secure attachment bonds, measured as a trait construct, are associated with behaviors that facilitate intimacy, such as physical touch and self-disclosure (Brennan et al. 1998; Chopik et al. 2014; Laurenceau et al. 1998). Perhaps such bonds also refocus the effects of estradiol away from dominant or competitive behaviors and toward nurturant intimacy behaviors (Eastwick 2009).

Secure attachment bonds may also moderate estradiol responses to emotionally intimate situations. Edelstein et al. (2012) examined estradiol responses as a function of viewing an emotionally intimate video clip depicting a parent-child interaction. Women who were more avoidantly attached showed smaller increases in estradiol in response to watching this interaction. Women's avoidance was not related to their estradiol responses to watching emotionally positive (but not intimate) or neutral clips, suggesting that these effects were specific to emotionally intimate stimuli. Moreover, men's avoidance was unrelated to their estradiol responses across conditions, suggesting that the associations observed in this study may be specific to women. More generally, this study provides additional evidence for the hypothesis that secure 
attachment bonds might moderate the association between intimacy motivation and estradiol concentrations.

Data collected from women across the span of their ovulatory cycles provide especially compelling evidence that attachment bonds moderate the effects of estradiol in interpersonal relationships. Estradiol increases exponentially as women approach ovulation and are most likely to conceive (M. H. Johnson and Everitt 2000), suggesting that ovulatory shifts in women's behavior may reflect changes in endogenous estradiol levels. Eastwick and Finkel (2012) found that, among women who had stronger attachment bonds to their current romantic partners (measured by the Attachment Features and Functions scale; Tancredy and Fraley 2006), probability of conception (indexed by a self-report of the day the menstrual cycle was expected to begin) was positively associated with reports of physical intimacy. For women with weaker attachment bonds, the association between probability of conception and physical intimacy was negative, but non-significant. In a second study, Eastwick and Finkel (2012) found that for women who had weaker attachment bonds to their romantic partners, probability of conception was negatively related to sexual intimacy motives (e.g., "I would like to engage in romantic physical contact (e.g., kissing or other sexual activities) with [my partner] to become closer with him/her.") Among women who had stronger attachment bonds to their partners, the association between probability of conception and sexual intimacy motives was positive, but non-significant. Taken together, these studies indicate that women report more physical intimacy when they are most likely to conceive, but only when they are more strongly attached to their romantic partners. When women have weaker attachment bonds to their partners, greater likelihood of conception may actually inhibit physically intimate behaviors. Although hormone levels were not directly measured in these studies, it is possible that ovulatory changes in estradiol (or other relevant hormones) are implicated in the behavioral changes that were observed. Future research on the connection between attachment bonds, intimate behaviors, and estradiol should make an effort to directly measure estradiol because: 1) self-reports of menstrual cycle timing can yield unreliable data (Jukic et al. 2008; Small et al. 2007; Wood et al. 2014), and 2) the direct link between menstrual cycle phase and women's mate preferences has been challenged by many researchers (see Harris 2011, 2013; Harris et al. 2013; Wood et al. 2014).

\section{Summary}

Estradiol levels and responses appear to be associated with the strength and type of attachment bonds between adult romantic partners. When attachment bonds are strong and estradiol concentrations are high, people may be more likely to engage in behaviors directed toward establishing intimate bonds. When attachment bonds are weak and estradiol concentrations are high, people may be less likely to engage in behaviors directed toward establishing intimacy. In a long-term sense, attachment orientation may affect how people perceive their current relationships as well as how they perceive potential alternative partners, which may have downstream consequences for the expression of estradiol in the context of close relationships. Partners who are not securely attached may generally be less attuned to opportunities for intimacy. For these individuals, increases in estradiol may be channeled more toward mating effort (e.g., dominance behaviors, sexual competition) versus bonding effort (e.g., nurturance 
behaviors, intimacy motivation). More work is needed, however, to fully understand how the psychological adaptation of romantic attachment may dampen or refocus the effects of estradiol on evolutionarily older systems such as dominance and sexual motivation.

\section{Conclusions and Future Directions}

Our review and synthesis of the literature suggests that more recent evolutionary processes, such as romantic commitment and adult romantic pair-bonds, may influence hormonal mechanisms associated with older evolutionary processes (e.g., aggressive and dominant behaviors). In particular, we focused on the steroid hormones testosterone and estradiol because each of these hormones is implicated in short- and long-term mating behaviors and goals. We argue that psychological commitment and attachment to romantic partners may have evolved to play a role in transforming short-term mating relationships into long-term romantic pair-bonds via their modulation of these reproductive hormones. It is critical that future work in this domain take a more nuanced approach to studying the relationship between multiple relevant hormones and mating/ relationship behaviors. This approach is most possible via the adoption of appropriately rigorous research practices from both endocrine and relationship science (Loving and Campbell 2011).

It will also be important moving forward to include both men and women when studying links between endocrine function and adult human relationships, especially when considering hormones such as testosterone and estradiol. Estradiol is often thought of as a "feminine" hormone and testosterone as a "masculine" hormone. Thus, men are often excluded from estradiol -related research and women from testosterone-related research. Only more recently have women been included in studies examining testosterone and human relationships (e.g., Edelstein et al. 2011, 2014, in press; van Anders and Goldey 2010; van Anders et al. 2007; van Anders and Watson 2006) and men in studies examining estradiol and human relationships (Edelstein et al. 2012, 2010, 2014; Goldey et al. 2013; van Anders and Dunn 2009). As a result of the limited research examining both genders/sexes in the context of hormones and human relationships, it is often difficult if not impossible to parse apart which effects are specific to one or both genders/sexes.

Further, research that merges endocrine and relationship sciences, such as examining the association between individuals' testosterone and relationship quality, should begin to consider research designs that provide insight into the direction of causality. For instance, previous research demonstrates associations between men and women's testosterone levels and their degree of commitment and satisfaction to a romantic relationship (Edelstein et al. 2014). What close relationship researchers do not yet know is whether changes in testosterone predict changes in commitment and satisfaction, or the extent to which such links are bidirectional. Fortunately, relationship scientists regularly employ complex, longitudinal designs that follow individuals and/ or couples across many of the relationship transitions noted in this review (see Loving and Campbell 2011). The additional costs notwithstanding, such studies could incorporate repeated assessments of target hormones to provide information about the (bi)directional association between relationship phenomenon (e.g., attachment, 
commitment) and hormonal processes across different relationship stages (e.g., transitioning between short-and long-term partnerships).

As previously noted in Loving et al. (2006) as well as in Smith et al. (2009) more attention should be paid by relationship scientists towards the identification of psychological "mechanisms" that underlie close relationships and hormonal processes. As we already mentioned, previous research demonstrates a link between an individual's hormones and their level of (and/or their partner's level of) commitment to a romantic relationship (Edelstein et al. 2014). In the current review, we move one step further and suggest that specific psychological aspects of human psychology (e.g., commitment) may modulate testosterone in humans. We, along with others (e.g., van Anders and Goldey 2010), point out that specific psychological aspects might be more strongly associated with hormones than broader psychological categories. For example, perhaps sexual exclusivity or engaging in sex with only one partner, rather than relationship status per se, is most important for modulating testosterone in humans across various cultures. Digging deeper into the specific aspects of relationship constructs that are associated with hormones will move relationship scientists closer to identifying the potential "mechanisms" that may be responsible for the close relationship-hormone link.

Finally, the vast majority of research that we reviewed here-although focused on inherently dyadic processes and relationships (e.g., couples, parent-child pairs) involves data collected from individuals rather than dyads. Although individual-level data are certainly informative, dyadic data can help us better understand how relationships unfold in the real world. Relationship scientists have made important methodological advances in the realm of dyadic research - understanding how to collect, analyze, and interpret results that center around the idea that one person's psychological outcomes influence those of another (e.g., Edelstein et al. 2014). Neuroendocrine researchers could similarly consider both couple members of the dyad and how their hormone levels may be non-independent. Actor-partner interactions and latent variable approaches to dyadic models should be tested when considering research with dyads (Kenny et al. 2006); these analytic approaches can easily accommodate neuroendocrine assessments, including those that occur repeatedly over time (e.g., Edelstein et al., in press). For example, using these dyadic techniques, researchers are able to begin to examine how partners affect each other's health, such as how partners' hormonal processes are intertwined (Reed et al. 2013). It is only through such a concerted effort that many of the ideas we advance in this review can be fully and adequately tested empirically.

In sum, we examined the ways in which physiology and psychology interact to promote short- versus long-term mating. First we explored the hormonal processes related to short-term mating that are common across species: attracting mates, competing for mates, and gaining sexual access to mates. We suggested that hormonal processes that function to facilitate or promote short-term mating behaviors are "evolutionarily old" and have evolved deep in our evolutionary past. We then moved on to an exploration of long-term, pair-bonded relationships, and discussed more recent evolutionary adaptations that are relational or psychological in nature, and which are possibly unique to humans. In particular, we focused on the steroid hormones testosterone and estradiol because each of these hormones is implicated in short- and longterm mating behaviors and goals. Ultimately, we argue that new psychological adaptations such as romantic commitment and attachment might interact with testosterone 
and estradiol to facilitate the transformation of short-term mating relationships into long-term pair-bonds.

Ethical Standards The manuscript does not contain clinical studies or patient data.

Conflict of Interest The authors declare that they have no conflict of interest.

\section{References}

Ainsworth, M. D. S. (1989). Attachments beyond infancy. American Psychologist, 44(4), 709-716.

Antonio-Cabrera, E., \& Paredes, R. G. (2012). Effects of chronic estradiol or testosterone treatment upon sexual behavior in sexually sluggish male rats. Pharmacology, Biochemistry, and Behavior, 101, 336341.

Archer, J. (2009). Does sexual selection explain human sex differences in aggression? Behavioral and Brain Sciences, 32, 249-366.

Archer, J., Graham-Kevan, N., \& Davies, M. (2005). Testosterone and aggression: a reanalysis of book, Starzyk, and Quinsey's (2001) study. Aggression and Violent Behavior, 10, 241-261.

Arriaga, X. B., \& Agnew, C. R. (2001). Being committed: affective, cognitive, and conative components of relationship commitment. Personality and Social Psychology Bulletin, 27, 1190-1203.

Atance, C. M., \& O'Neill, D. K. (2001). Episodic future thinking. Trends in Cognitive Sciences, 5, 533-539.

August, G. P., Grumbach, M. M., \& Kaplan, S. L. (1972). Hormonal changes in puberty: Iii. Correlation of plasma testosterone, $\mathrm{lh}$, fsh, testicular size, and bone age with male pubertal development. The Journal of Clinical Endocrinology and Metabolism, 34, 319-326.

Augustine, J.K., Millspaugh, J.J., \& Sandercock, B.K. (2011). Testosterone mediates mating success in greater prairie-chickens. In B. K. Sandercock, K. Martin, \& G. Segelbacher (Eds.), Ecology, conservation, and management of grouse. Studies in avian biology (Vol. 39, pp. 195-208). Berkely, CA: University of California Press.

Barash, D. (1977). Sociobiology and behavior. New York: Elsevier.

Barrett, E. S., Tran, V., Thurston, S., Jasienska, G., Furberg, A. S., Ellison, P. T., \& Thune, I. (2013). Marriage and motherhood are associated with lower testosterone concentrations in women. Hormones and Behavior, 63, 72-79.

Barta, W. D., \& Kiene, S. M. (2005). Motivations for infidelity in heterosexual dating couples: the roles of gender, personality differences, and sociosexual orientation. Journal of Social and Personal Relationships, 22, 339-360.

Beehner, J. C., Bergman, T. J., Cheney, D. L., Seyfarth, R. M., \& Whitten, P. L. (2006). Testosterone predicts future dominance rank and mating activity among male chacma baboons. Behavioral Ecology and Sociobiology, 59, 469-479.

Behringer, V., Deschner, T., Deimel, C., Stevens, J. M. G., \& Hohmann, G. (2014). Age-related changes in urinary testosterone levels suggest differences in puberty onset and divergent life history strategies in bonobos and chimpanzees. Hormones and Behavior, 66, 525-533.

Berg, S. J., \& Wynne-Edwards, K. E. (2001). Changes in testosterone, cortisol, and estradiol levels in men becoming fathers. Mayo Clinic Proceedings, 76, 582-592.

Booth, A., \& Dabbs, J. M. (1993). Testosterone and men's marriages. Social Forces, 72, 463-477.

Bouissou, M. F. (1990). Effects of estrogen treatment on dominance relationships in cows. Hormones and Behavior, 24, 376-387.

Bowlby, J. (1969). Attachment and loss: Vol. I. Attachment. London: Hogarth

Brennan, K. A., Wu, S., \& Loev, J. (1998). Adult romantic attachment and individual differences in attitudes toward physical contact in the context of adult romantic relationships. In J. A. Simpson \& W. S. Rholes (Eds.), Attachment theory and close relationships (pp. 394-428). New York: Guilford Press. 
Burnham, T. C., Chapman, J. F., Gray, P. B., McIntyre, M. H., Lipson, S. F., \& Ellison, P. T. (2003). Men in committed, romantic relationships have lower testosterone. Hormones and Behavior, 44, 119-122.

Buss, D. M., \& Schmitt, D. P. (1993). Sexual strategies theory: an evolutionary perspective on human mating. Psychological Review, 100, 204-232.

Carter, C. S., \& Keverne, E. B. (2002). The neurobiology of social affiliation and pair bonding. In D. W. Pfaff, A. P. Arnold, A. M. Etgen, S. E. Fahrbach, \& R. T. Rubin (Eds.), Hormones, brain and behavior (1st ed., Vol. 1, pp. 299-337). New York: Academic Press.

Cassidy, J. (2000). Adult romantic attachments: a developmental perspective on individual differences. Review of General Psychology, 4, 111-131.

Champagne, F., Diorio, J., Sharma, S., \& Meaney, M. J. (2001). Naturally occurring variations in maternal behavior in the rat are associated with differences in estrogen-inducible central oxytocin receptors. Proceedings of the National Academy of Sciences, 98, 12736-12741.

Chevalier-Skolnikoff, S. (1974). Male-female, female-female, and male-male sexual behavior in the stumptail monkey, with special attention to the female orgasm. Archives of Sexual Behavior, 3, 95-116.

Chopik, W. J., Edelstein, R. S., van Anders, S. M., Wardecker, B. M., Shipman, E. L., \& Samples-Steele, C. R. (2014). Too close for comfort? Adult attachment and cuddling in romantic and parent-child relationships. Personality and Individual Differences, 69, 212-216.

Cieri, R. L., Churchill, S. E., Franciscus, R. G., Tan, J., \& Hare, B. (2014). Craniofacial feminization, social tolerance, and the origins of behavioral modernity. Current Anthropology, 55, 419-443.

Cushing, B. S., Perry, A., Musatov, S., Ogawa, S., \& Papademetriou, E. (2008). Estrogen receptors in the medial amygdala inhibit the expression of male prosocial behavior. Journal of Neuroscience, 41, 10399 10403.

deCatanzaro, D., Khan, A., Berger, R. G., \& Lewis, E. (2009). Exposure to developing females induces polyuria, polydipsia, and altered urinary levels of creatinine, $17 \beta$-estradiol, and testosterone in adult male mice (mus musculus). Hormones and Behavior, 55, 240-247.

Diamond, L. M., \& Wallen, K. (2011). Sexual minority women's sexual motivation around the time of ovulation. Archives of Sexual Behavior, 40, 237-246.

Drefahl, S. (2012). Do the married really live longer? The role of cohabitation and socioeconomic status. Journal of Marriage and Family, 74, 462-475.

Drigotas, S. M., \& Rusbult, C. E. (1992). Should I stay or should I go? A dependence model of breakups. Journal of Personality and Social Psychology, 62, 62-87.

Eastwick, P. W. (2009). Beyond the pleistocene: using phylogeny and constraint to inform the evolutionary psychology of human mating. Psychological Bulletin, 135, 794-821.

Eastwick, P. W., \& Finkel, E. J. (2012). The evolutionary armistice: attachment bonds moderate the function of ovulatory cycle adaptations. Personality and Social Psychology Bulletin, 38, 174-184.

Edelstein, R. S., Stanton, S. J., Henderson, M. M., \& Sanders, M. R. (2010). Endogenous estradiol levels are associated with attachment avoidance and implicit intimacy motivation. Hormones and Behavior, 57, 230-236.

Edelstein, R. S., Chopik, W. J., \& Kean, E. L. (2011). Sociosexuality moderates the association between testosterone and relationship status in men and women. Hormones and Behavior, 60, 248-255.

Edelstein, R. S., Kean, E. L., \& Chopik, W. J. (2012). Women with an avoidant attachment style show attenuated estradiol responses to emotionally intimate stimuli. Hormones and Behavior, $61,167-175$.

Edelstein, R. S., van Anders, S. M., Chopik, W. J., Goldey, K. L., \& Wardecker, B. M. (2014). Dyadic associations between testosterone and relationship quality in couples. Hormones and Behavior, 65, 401407.

Fales, M. R., Gildersleeve, K. A., \& Haselton, M. G. (2014). Exposure to perceived male rivals raises men's testosterone on fertile relative to nonfertile days of their partner's ovulatory cycle. Hormones and Behavior, 65, 454-460.

Faruzzi, A. N., Solomon, M. B., Demas, G. E., \& Huhman, K. L. (2005). Gonadal hormones modulate the display of submissive behavior in socially defeated female syrian hamsters. Hormones and Behavior, 47, $569-575$.

Fernandez-Duque, E., Valeggia, C. R., \& Mendoza, S. P. (2009). The biology of paternal care in human and nonhuman primates. Annual Review of Anthropology, 38, 115-130.

Finkel, E. J., Rusbult, C. E., Kumashiro, M., \& Hannon, P. A. (2002). Dealing with betrayal in close relationships: does commitment promote forgiveness? Journal of Personality and Social Psychology, $82,956-974$.

Fisher, H. E. (1998). Lust, attraction, and attachment in mammalian reproduction. Human Nature, 9, $23-52$. 
Fleming, A. S., Ruble, D., Krieger, H., \& Wong, P. Y. (1997). Hormonal and experiential correlates of maternal responsiveness during pregnancy and the puerperium in human mothers. Hormones and Behavior, 31, 145-158.

Fraley, R.C., \& Shaver, P. R. (2000). Adult romantic attachment: theoretical developments, emerging controversies, and unanswered questions. Review of General Psychology, 4, 132-154.

Fraley, R.C., Brumbaugh, C. C., \& Marks, M. J. (2005). The evolution and function of adult attachment: a comparative and phylogenetic analysis. Journal of Personality and Social Psychology, 89, 731-746.

Gangestad, S. W., \& Simpson, J. A. (2000). The evolution of human mating: trade-offs and strategic pluralism. Behavioral and Brain Sciences, 23, 573-587.

Gannon, T.A., \& Ward, T. (2008). Rape: Psychopathology and theory. In D. R. Laws \& W. T. O'Donohue (Eds.), Sexual deviance: Theory, assessment, and treatment (pp. 336-355). New York, NY:Guilford Press.

Geary, D. C. (2010). Competing for mates. In D. C. Geary (Ed.), Male, female: The evolution of human sex differences (2nd ed., pp. 213-245). Washington: American Psychological Association.

Gettler, L. T., McDade, T. W., Feranil, A. B., \& Kuzawa, C. W. (2011). Longitudinal evidence that fatherhood decreases testosterone in human males. Proceedings of the National Academy of Sciences, 108(39), 16194-16199.

Gilbert, D. T., \& Wilson, T. D. (2007). Prospection: Experiencing the future. Science, 317, 1351-1354.

Girard-Buttoz, C., Heistermann, M., Krummel, S., \& Engelhardt, A. (2009). Seasonal and social influences on fecal androgen and glucocorticoid excretion in wild male long-tailed macaques (macaca fascicularis). Physiology \& Behavior, 98, 168-175.

Goldey, K. L., Avery, L. R., \& van Anders, S. M. (2013). Sexual fantasies and gender/sex: A multimethod approach with quantitative content analysis and hormonal responses. Journal of Sex Research, 0, 1-15. doi:10.1080/00224499.2013.798611.

Gray, P. B. (2003). Marriage, parenting, and testosterone variation among kenyan swahili men. American Journal of Physical Anthropology, 122, 279-286.

Gray, P. B., Kahlenberg, S. M., Barrett, E. S., Lipson, S. F., \& Ellison, P. T. (2002). Marriage and fatherhood are associated with lower testosterone in males. Evolution and Human Behavior, 23, 193-201.

Gray, P. B., Yang, C.-F. J., \& Pope, H. G. (2006). Fathers have lower salivary testosterone levels than unmarried men and married non-fathers in Beijing, China. Proceedings of the Royal Society B: Biological Sciences, 273, 333-339.

Hackathorn, J., \& Brantley, A. (2014). To know you is (not) to want you: mediators between sociosexual orientation and romantic commitment. Current Psychology, 33, 89-97.

Harris, C. (2011). Menstrual cycle and facial preferences reconsidered. Sex Roles, 64, 669-681.

Harris, C. (2013). Shifts in masculinity preferences across the menstrual cycle: still not there. Sex Roles, 69, $507-515$.

Harris, C., Chabot, A., \& Mickes, L. (2013). Shifts in methodology and theory in menstrual cycle research on attraction. Sex Roles, 69, 525-535.

Hau, M. (2007). Regulation of male traits by testosterone: Implications for the evolution of vertebrate life histories. Bioessays, 29, 133-144.

Hawkes, K. (2004). Mating, parenting, and the evolution of human pair bonds. In B. Chapais \& C. Berman (Eds.), Kinship and behavior in primates. Oxford: Oxford University Press.

Hazan, C., \& Shaver, P.R. (1987). Romantic love conceptualized as an attachment process. Journal of Personality and Social Psychology, 52, 511-524.

Hazan, C., \& Zeifman, D. (1994). Sex and the psychological tether. In K. Bartholomew \& D. Perlman (Eds.), Attachment processes in adulthood (pp. 151-178). London: Jessica Kingsley Publishers.

Hirschenhauser, K., \& Oliveira, R. F. (2006). Social modulation of androgens in male vertebrates: metaanalyses of the challenge hypothesis. Animal Behaviour, 71, 265-277.

Hirschenhauser, K., Frigerio, D., Grammer, K., \& Magnusson, M. S. (2002). Monthly patterns of testosterone and behavior in prospective fathers. Hormones and Behavior, 42, 172-181.

Hohmann, G., \& Fruth, B. (2003). Intra-and inter-sexual aggression by bonobos in the context of mating. Behaviour, 140, 1389-1414.

Hooper, A. E. C., Gangestad, S. W., Thompson, M. E., \& Bryan, A. D. (2011). Testosterone and romance: the association of testosterone with relationship commitment and satisfaction in heterosexual men and women. American Journal of Human Biology, 23, 553-555.

Howland, B. E., Sanford, L. M., \& Palmer, W. M. (1985). Changes in serum levels of lh, fsh, prolactin, testosterone, and cortisol associated with season and mating in male pygmy goats. Journal of Andrology, 6, 89-96. 
Hui, C. M., Finkel, E. J., Fitzsimons, G. M., Kumashiro, M., \& Hofmann, W. (2014). The Manhattan effect: when relationship commitment fails to promote support for partners' interests. Journal of Personality and Social Psychology, 106, 546-570.

Jankowiak, W. R., \& Fischer, E. F. (1992). A cross-cultural perspective on romantic love. Ethnology, 31, 149155.

Johnson, M. H., \& Everitt, B. J. (2000). Essential reproduction. Oxford: Blackwell Science.

Johnson, N. J., Backlund, E., Sorlie, P. D., \& Loveless, C. A. (2000). Marital status and mortality: the national longitudinal mortality study. Annals of Epidemiology, 10, 224-238.

Jukic, A. M. Z., Weinberg, C. R., Wilcox, A. J., McConnaughey, D. R., Hornsby, P., \& Baird, D. D. (2008). Accuracy of reporting of menstrual cycle length. American Journal of Epidemiology, 167, 25-33.

Kenny, D. A., Kashy, D. A., \& Cook, W. L. (2006). Dyadic data analysis. New York: Guilford Press.

Kenrick, D.T., \& Trost, M.R. (1997). Evolutionary approaches to relationships. In S. Duck (Ed.), Handbook of personal relationships: Theory, research and interventions (2nd ed) (pp.151-177). Hoboken, NJ: John Wiley \& Sons Inc.

Kenrick, D. T., Griskevicius, V., Neuberg, S. L., \& Schaller, M. (2010). Renovating the pyramid of needs: contemporary extensions built upon ancient foundations. Perspectives on Psychological Science, 5, 292314.

Kenrick, D. T., Neuberg, S. L., \& White, A. E. (2013). Relationships from an evolutionary life history perspective. In J. A. Simpson \& L. Campbell (Eds.), The oxford handbook of close relationships (pp. 1338). New York: Oxford University Press.

Kiecolt-Glaser, J. K., \& Newton, T. L. (2001). Marriage and health: his and hers. Psychological Bulletin, 127, $472-503$.

Kleiman, D. G. (1977). Monogamy in mammals. The Quarterly Review of Biology, 52, 39-69.

Konkle, A. T., \& McCarthy, M. M. (2011). Developmental time course of estradiol, testosterone, and dihydrotestosterone levels in discrete regions of male and female rat brain. Endocrinology, $152,223-235$.

Koss, M. P., Gidycz, C. A., \& Wisniewski, N. (1987). The scope of rape: Incidence and prevalence of sexual aggression and victimization in a national sample of higher education students. Journal of Consulting and Clinical Psychology, 55, 162-170.

Kuzawa, C. W., Gettler, L. T., Muller, M. N., McDade, T. W., \& Feranil, A. B. (2009). Fatherhood, pairbonding and testosterone in the philippines. Hormones and Behavior, 56, 429-435.

Kuzawa, C. W., Gettler, L. T., Huang, Y., \& McDade, T. W. (2010). Mothers have lower testosterone than nonmothers: evidence from the Philippines. Hormones and Behavior, 57(4), 441-447.

Laurenceau, J. P., Barrett, L. F., \& Pietromonaco, P. R. (1998). Intimacy as an interpersonal process: the importance of self-disclosure, partner disclosure, and perceived partner responsiveness in interpersonal exchanges. Journal of Personality and Social Psychology, 74, 1238-1251.

Le, B., \& Agnew, C. R. (2003). Commitment and its theorized determinants: a meta-analysis of the investment model. Personal Relationships, 10, 37-57.

Le, B., Korn, M.S., Crockett, E.E., \& Loving, T.J. (2010). Missing you maintains us: Missing a romantic partner, commitment, relationship maintenance, and physical infidelity. Journal of Social and Personal Relationships, 28(5), 653-667.

Lindenfors, P., \& Tullberg, B. S. (2011). Evolutionary aspects of aggression the importance of sexual selection. Advances in Genetics, 75, 7-22.

López, H. H., Hay, A. C., \& Conklin, P. H. (2009). Attractive men induce testosterone and cortisol release in women. Hormones and Behavior, 56, 84-92.

Loving, T. J., \& Campbell, L. (2011). Mind-body connections in personal relationships: what close relationships researchers have to offer. Personal Relationships, 18, 165-169.

Loving, T. J., Heffner, K. L., \& Kiecolt-Glaser, J. K. (2006). Physiology and interpersonal relationships. In A. Vangelisti \& D. Perlman (Eds.), Cambridge handbook of personal relationships (pp. 385-405). New York: Cambridge University Press.

Maestripieri, D. (1997). Gestural communication in macaques: usage and meaning of nonvocal signals. Evolution of Communication, 1, 193-222.

Maestripieri, D. (2005). Gestural communication in three species of macaques (macaca mulatta, $\mathrm{m}$. Nemestrina, m. Arctoides): use of signals in relation to dominance and social context. Gesture, 5, 57-73.

Maestripieri, D., \& Zehr, J. L. (1998). Maternal responsiveness increases during pregnancy and after estrogen treatment in macaques. Hormones and Behavior, 34, 223-230.

Markey, P., \& Markey, C. (2013). Sociosexuality and relationship commitment among lesbian couples. Journal of Research in Personality, 47, 282-285.

Mazur, A., \& Michalek, J. (1998). Marriage, divorce, and male testosterone. Social Forces, 77, 315-330. 
McIntyre, M., Gangestad, S. W., Gray, P. B., Chapman, J. F., Burnham, T. C., O'Rourke, M. T., \& Thornhill, R. (2006). Romantic involvement often reduces men's testosterone levels-but not always: the moderating role of extrapair sexual interest. Journal of Personality and Social Psychology, 91, 642-651.

Michael, R. P., \& Zumpe, D. (1993). A review of hormonal factors influencing the sexual and aggressive behavior of macaques. American Journal of Primatology, 30, 213-241.

Mileva-Seitz, V., \& Fleming, A. S. (2011). How mothers are born: A psychobiological analysis of mothering. In A. Booth, S. M. McHale, \& N. S. Landale (Eds.), Biosocial foundations of family processes (pp. 3-34). New York: Springer.

Miller, G.F. (1998). How mate choice shaped human nature: A review of sexual selection and human evolution. In C. Crawford \& D. Krebs (Eds.), Handbook of evolutionary psychology: Ideas, issues, and applications (pp. 87-129). New York, NY: Psychology Press.

Muller, M. N., Kahlenberg, S. M., \& Wrangham, R. (2009a). Male aggression against females and sexual coercion in chimpanzees sexual coercion in primates and humans: An evolutionary perspective on male aggression against females (pp. 184-217). Cambridge: Harvard University Press.

Muller, M. N., Marlowe, F. W., Bugumba, R., \& Ellison, P. T. (2009b). Testosterone and paternal care in East African foragers and pastoralists. Proceedings of the Royal Society B: Biological Sciences, 276, 347-354.

Muller, M. N., Thompson, M. E., Kahlenberg, S. M., \& Wrangham, R. W. (2011). Sexual coercion by male chimpanzees shows that female choice may be more apparent than real. Behavioral Ecology and Sociobiology, 65, 921-933.

Netter, P. (2004). Personality and hormones. In R. M. Stelmack (Ed.), On the psychobiology of personality: Essays in honor of marvin zuckerman (pp. 353-377). Oxford: Elsevier.

Newman, S. W. (1999). The medial extended amygdala in male reproductive behavior. A node in the mammalian social behavior network. Annals of the New York Academy of Sciences, 877, 242-257.

Numan, M. (1994). A neural circuitry analysis of maternal behavior in the rat. Acta Paediatrica, 397, 19-28.

Ogawa, S., Chester, A. E., Hewitt, S. C., Walker, V. R., Gustafsson, J.-Å., Smithies, O., \& Pfaff, D. W. (2000). Abolition of male sexual behaviors in mice lacking estrogen receptors $\alpha$ and $\beta$ ( $\alpha \beta$ erko). Proceedings of the National Academy of Sciences, 97, 14737-14741.

Oriña, M. M., Collins, W. A., Simpson, J. A., Salvatore, J. E., Haydon, K. C., \& Kim, J. S. (2011). Developmental and dyadic perspectives on commitment in adult romantic relationships. Psychological Science, 22, 908-915.

Ostovich, J. M., \& Sabini, J. (2004). How are sociosexuality, sex drive, and lifetime number of sexual partners related? Personality and Social Psychology Bulletin, 30, 1255-1266.

Ottinger, M. A., \& Brinkley, H. J. (1978). Testosterone and sex-related behavior and morphology: relationship during maturation and in the adult Japanese quail. Hormones and Behavior, 11, 175-182.

Penke, L., \& Asendorpf, J. (2008). Beyond global sociosexual orientations: a more differentiated look at sociosexuality and its effects on courtship and romantic relationships. Journal of Personality and Social Psychology, 95, 1113-1135.

Pfaff, D. W. (1980). Estrogens and brain function: Neural analysis of a hormone-controlled mammalian reproductive behavior. New York: Springer.

Pollet, T. V., Cobey, K. D., \& van der Meij, L. (2013). Testosterone levels are negatively associated with childlessness in males, but positively related to offspring count in fathers. PloS One, 8, e60018.

Pope, N. S., Wilson, M. E., \& Gordon, T. P. (1987). The effect of season on the induction of sexual behavior by estradiol in female rhesus monkeys. Biology of Reproduction, 36, 1047-1054.

Pryce, C. R. (1996). Socialization, hormones, and the regulation of maternal behavior in nonhuman simian primates. Advances in The Study of Behavior, 25, 423-473.

Reburn, C. J., \& Wynne-Edwards, K. E. (1999). Hormonal changes in males of a naturally biparental and a uniparental mammal. Hormones and Behavior, 35, 163-176.

Reed, R. G., Randall, A. K., Post, J. H., \& Butler, E. A. (2013). Partner influence and in-phase versus antiphase physiological linkage in romantic couples. International Journal of Psychophysiology, 88, 309316.

Rissman, E. F., Early, A. H., Taylor, J. A., Korach, K. S., \& Lubahn, D. B. (1997). Estrogen receptors are essential for female sexual receptivity. Endocrinology, 138, 507-510.

Roney, J. R., Lukaszewski, A. W., \& Simmons, Z. L. (2007). Rapid endocrine responses of young men to social interactions with young women. Hormones and Behavior, 52, 326-333.

Rosenblatt, J. S., Olufowobi, A., \& Siegel, H. I. (1998). Effects of pregnancy hormones on maternal responsiveness, responsiveness to estrogen stimulation of maternal behavior, and the lordosis response to estrogen stimulation. Hormones and Behavior, 33, 104-114.

Rusbult, C. E., Martz, J. M., \& Agnew, C. R. (1998). The investment model scale: measuring commitment level, satisfaction level, quality of alternatives, and investment size. Personal Relationships, 5, 357-387. 
Saginor, M., \& Horton, R. (1968). Reflex release of gonadotropin and increased plasma testosterone concentration in male rabbits during copulation. Endocrinology, 82, 627-630.

Schacter, D. L., Addis, D. R., \& Buckner, R. L. (2007). Remembering the past to imagine the future: the prospective brain. Nature Reviews Neuroscience, 8, 657-661.

Schultheiss, O. C. (2008). Implicit motives. In O. P. John, R. W. Robins, \& L. A. Pervin (Eds.), Handbook of personality: Theory and research (3rd ed., pp. 603-633). New York: Guilford Press.

Schultheiss, O. C., Dargel, A., \& Rohde, W. (2003). Implicit motives and sexual motivation and behavior. Journal of Research in Personality, 37, 224-230.

Shaver, P. R., \& Mikulincer, M. (2007). Attachment theory and research: Core concepts, basic principles, conceptual bridges. In A. W. Kruglanski \& E. T. Higgins (Eds.), Social psychology: Handbook of basic principles (2nd ed., pp. 650-677). New York: Guilford Press.

Simpson, J. A., \& Belsky, J. (2008). Attachment theory within a modern evolutionary framework. In J. Cassidy \& P. R. Shaver (Eds.), Handbook of attachment: Theory, research, and clinical applications (2nd ed., pp. 131-157). New York: Guilford Press.

Simpson, J. A., \& Gangestad, S. W. (1991). Individual differences in sociosexuality: evidence for convergent and discriminant validity. Journal of Personality and Social Psychology, 60, 870-883.

Simpson, J. A., \& Gangestad, S. W. (1992). Sociosexuality and romantic partner choice. Journal of Personality, 60, 31-51.

Simpson, J. A., \& Rholes, W. S. (2012). Adult attachment orientations, stress, and romantic relationships. Advances in Experimental Social Psychology, 45, 279-328.

Sizonenko, P. C., \& Paunier, L. (1975). Hormonal changes in puberty iii: correlation of plasma dehydroepiandrosterone, testosterone, fsh, and lh with stages of puberty and bone age in normal boys and girls and in patients with addison's disease or hypogonadism or with premature or late adrenarche. The Journal of Clinical Endocrinology and Metabolism, 41, 894-904.

Slatcher, R. B., Mehta, P. H., \& Josephs, R. A. (2011). Testosterone and self-reported dominance interact to influence human mating behavior. Social Psychological and Personality Science, 2, 531-539.

Slotter, E. B., Finkel, E. J., DeWall, C. N., Pond, R. S., Jr., Lambert, N. M., Bodenhausen, G. V., \& Fincham, F. D. (2012). Putting the brakes on aggression toward a romantic partner: the inhibitory influence of relationship commitment. Journal of Personality and Social Psychology, 102, 291-305.

Small, C. M., Manatunga, A. K., \& Marcus, M. (2007). Validity of self-reported menstrual cycle length. Annals of Epidemiology, 17, 163-170.

Smith, A. M., Loving, T. J., Crockett, E. E., \& Campbell, L. (2009). What's closeness got to do with it? Men's and women's cortisol responses when providing and receiving support. Psychosomatic Medicine, 71, 843-851.

Smuts, B. B., \& Smuts, R. W. (1993). Male aggression and sexual coercion of females in nonhuman primates and other mammals: evidence and theoretical implications. Advances in the Study of Behavior, 22, 1-63.

Snowdon, C. T. (1996). Parental care in cooperatively breeding species. In J. S. Rosenblatt \& C. T. Snowdon (Eds.), Parental care: Evolution, mechanisms, and adaptive significance (pp.643-89). San Diego, CA: Academic Press.

Sobolewski, M. E., Brown, J. L., \& Mitani, J. C. (2012). Territoriality, tolerance and testosterone in wild chimpanzees. Animal Behaviour, 84, 1469-1474.

Stanton, S. J., \& Edelstein, R. S. (2009). The physiology of women's power motive: implicit power motivation is positively associated with estradiol levels in women. Journal of Research in Personality, 43, 11091113.

Stanton, S. J., \& Schultheiss, O. C. (2007). Basal and dynamic relationships between implicit power motivation and estradiol in women. Hormones and Behavior, 52, 571-580.

Stanton, S. J., \& Schultheiss, O. C. (2009). The hormonal correlates of implicit power motivation. Journal of Research in Personality, 43, 942-949.

Suddendorf, T., Addis, D. R., \& Corballis, M. C. (2009). Mental time travel and the shaping of the human mind. Philosophical Transactions of the Royal Society, B: Biological Sciences, 364, 1317-1324.

Surbeck, M., Deschner, T., Schubert, G., Weltring, A., \& Hohmann, G. (2012). Mate competition, testosterone and intersexual relationships in bonobos. Animal Behaviour, 83, 659-669.

Szpunar, K. K., Watson, J. M., \& McDermott, K. B. (2007). Neural substrates of envisioning the future. Proceedings of the National Academy of Sciences, 104, 642-647.

Tancredy, C. M., \& Fraley, R. C. (2006). The nature of adult twin relationships: an attachment-theoretical perspective. Journal of Personality and Social Psychology, 90, 78-93.

Teffer, K., \& Semendeferi, K. (2012). Human prefrontal cortex: evolution, development, and pathology. Progress in Brain Research, 195, 191-218. 
Trainor, B. C., \& Marler, C. A. (2002). Testosterone promotes paternal behaviour in a monogamous mammal via conversion to oestrogen. Proceedings. Biological sciences / The Royal Society, 269, 823-829.

Trainor, B. C., Kyomen, H. H., \& Marler, C. A. (2006). Estrogenic encounters: how interactions between aromatase and the environment modulate aggression. Frontiers in Neuroendocrinology, 27, 170-179.

Trainor, B. C., Finy, M. S., \& Nelson, R. J. (2008). Rapid effects of estradiol on male aggression depend on photoperiod in reproductively non-responsive mice. Hormones and Behavior, 53, 192-199.

Treas, J., \& Giesen, D. (2000). Sexual infidelity among married and cohabiting Americans. Journal of Marriage and Family, 62, 48-60.

Tulving, E. (2005). Episodic memory and autonoesis: Uniquely human? In H. S. Terrace \& J. Metcalfe (Eds.), The missing link in cognition: Origins of self-reflective consciousness (pp. 3-56). New York: Oxford University Press.

Twenge, J. M., Campbell, W. K., \& Foster, C. A. (2003). Parenthood and marital satisfaction: a meta-analytic review. Journal of Marriage and Family, 65, 574-583.

van Anders, S. M. (2009). Androgens and diversity and adult human partnering. In P. B. Gray \& P. T. Ellison (Eds.), Endocrinology of social relationships (pp. 340-363). Cambridge: Harvard University Press.

van Anders, S. M., \& Dunn, E. J. (2009). Are gonadal steroids linked with orgasm perceptions and sexual assertiveness in women and men? Hormones and Behavior, 56, 206-213.

van Anders, S. M., \& Goldey, K. L. (2010). Testosterone and partnering are linked via relationship status for women and 'relationship orientation' for men. Hormones and Behavior, 58, 820-826.

van Anders, S. M., \& Watson, N. V. (2006). Relationship status and testosterone in North American heterosexual and non-heterosexual men and women: cross-sectional and longitudinal data. Psychoneuroendocrinology, 31, 715-723.

van Anders, S. M., \& Watson, N. V. (2007). Testosterone levels in women and men who are single, in longdistance relationships, or same-city relationships. Hormones and Behavior, 51, 286-291.

van Anders, S. M., Hamilton, L. D., \& Watson, N. V. (2007). Multiple partners are associated with higher testosterone in North American men and women. Hormones and Behavior, 51, 454-459.

van Anders, S. M., Brotto, L., Farrell, J., \& Yule, M. (2009). Associations among physiological and subjective sexual response, sexual desire, and salivary steroid hormones in healthy premenopausal women. Journal of Sexual Medicine, 6, 739-751.

van Anders, S. M., Goldey, K. L., \& Kuo, P. X. (2011). The steroid/peptide theory of social bonds: integrating testosterone and peptide responses for classifying social behavioral contexts. Psychoneuroendocrinology, 36, 1265-1275.

van Anders, S. M., Edelstein, R. S., Wade, R. M., \& Samples-Steele, C. R. (2013). Descriptive experiences and sexual vs. Nurturant aspects of cuddling between adult romantic partners. Archives of Sexual Behavior, 42, 553-560.

van der Meij, L., Buunk, A. P., van de Sande, J. P., \& Salvador, A. (2008). The presence of a woman increases testosterone in aggressive dominant men. Hormones and Behavior, 54, 640-644.

van der Meij, L., Almela, M., Buunk, A. P., Fawcett, T. W., \& Salvador, A. (2011). Men with elevated testosterone levels show more affiliative behaviours during interactions with women. Proceedings of the Royal Society B: Biological Sciences, 1726, 202-208.

Van Lange, P. A., Rusbult, C. E., Drigotas, S. M., Arriaga, X. B., Witcher, B. S., \& Cox, C. L. (1997). Willingness to sacrifice in close relationships. Journal of Personality and Social Psychology, 72, 13731395.

Van Poppel, F., \& Joung, I. (2001). Long-term trends in marital status mortality differences in the netherlands 1850-1970. Journal of Biosocial Science, 33, 279-303.

vom Saal, F. (1983). Models of early hormonal effects on intrasex aggression in mice. In B. Svare (Ed.), Hormones and aggressive behavior (pp. 197-222). New York, NY: Springer.

Wallen, K., Winston, L. A., Gaventa, S., Davis-DaSilva, M., \& Collins, D. C. (1984). Periovulatory changes in female sexual behavior and patterns of ovarian steroid secretion in group-living rhesus monkeys. Hormones and Behavior, 18, 431-450.

Wieselquist, J., Rusbult, C. E., Foster, C. A., \& Agnew, C. R. (1999). Commitment, pro-relationship behavior, and trust in close relationships. Journal of Personality and Social Psychology, 77, 942-966.

Wingfield, J. C., Hegner, R. E., Dufty, A. M., \& Ball, G. F. (1990). The "challenge hypothesis": theoretical implications for patterns of testosterone secretion, mating systems, and breeding strategies. The American Naturalist, 136, 829-846.

Wobber, V., Hare, B., Lipson, S., Wrangham, R., \& Ellison, P. (2013). Different ontogenetic patterns of testosterone production reflect divergent male reproductive strategies in chimpanzees and bonobos. Physiology \& Behavior, 116-117, 44-53. 
Wolovich, C. K., Evans, S., \& French, J. A. (2008). Dads do not pay for sex but do buy the milk: food sharing and reproduction in owl monkeys (aotus spp.). Animal Behaviour, 75, 115-1163.

Wood, W., Kressel, L., Joshi, P. D., \& Louie, B. (2014). Meta-analysis of menstrual cycle effects on women's mate preferences. Emotion Review, 0, 1-21. doi:10.1177/1754073914523073.

Wu, M. V., Manoli, D. S., Fraser, E. J., Coats, J. K., Tollkuhn, J., Honda, S., \& Shah, N. M. (2009). Estrogen masculinizes neural pathways and sex-specific behaviors. Cell, 139, 61-72.

Wynne-Edwards, K. E. (2001). Hormonal changes in mammalian fathers. Hormones and Behavior, 40, 139145.

Wynne-Edwards, K. E., \& Reburn, C. J. (2000). Behavioral endocrinology of mammalian fatherhood. Trends in Ecology and Evolution, 15, 464-468.

Yeap, B. B., Almeida, O. P., Hyde, Z., Norman, P. E., Chubb, S. P., Jamrozik, K., \& Flicker, L. (2007). In men older than 70 years, total testosterone remains stable while free testosterone declines with age. The health in men study. European Journal of Endocrinology, 156, 585-594.

Yoshinaga, K., Hawkins, R. A., \& Stocker, J. F. (1969). Estrogen secretion by the rat ovary in vivo during the estrous cycle and pregnancy. Endocrinology, 85, 103-112.

Zehr, J. L., Maestripieri, D., \& Wallen, K. (1998). Estradiol increases female sexual initiation independent of male responsiveness in rhesus monkeys. Hormones and Behavior, 33, 95-103.

Zeifman, D., \& Hazan, C. (2008). Pair bonds as attachments: Reevaluating the evidence. In J. Cassidy \& P. R. Shaver (Eds.), Handbook of attachment theory, research, and clinical applications (2nd ed., pp. 436455). New York: Guilford Press.

Zumpe, D., \& Michael, R. P. (1989). Female dominance rank and behavior during artificial menstrual cycles in social groups of rhesus monkeys (macaca mulatta). American Journal of Primatology, 17, 287-304. 